\title{
PELATIHAN PEMBUATAN PAKAN BUATAN UNTUK ULAT SUTERA Samia cynthia Riccini
}

\author{
Dina Wahyu Trisnawati, Ihsan Nurkomar \\ Departemen Agroteknologi, Fakultas Pertanian, Universitas Muhammadiyah Yogyakarta \\ ihsan.nurkomar@umy.ac.id
}

\begin{abstract}
Silkworms are one of high economic value insects. Silkworm cocoon can be used as the base material for making silk fabric with a high selling price. Jantra Mas Sejahtera (JAMTRA) business group is a silk business group that conducts business from upstream to downstream independently ranging from rearing of silkworm, thread and silk processing, and silk fabric product design. In terms of the rearing of silkworms, JAMTRA business groups face problems such as a lack of understanding of how to rear insects properly, and a lack of knowledge about artificial fdiet for insect rearing. This activity aims to increase the knowledge of silkworm breeders in insects rearing based on the ecological nature of insects and training for silkworm breeders in making artificial diet. The results show that the artfical diet can be used for silkworms. However, no cocoons are formed. Thus, further activities are necessary to modify the artificial diet composition.
\end{abstract}

Keywords: artificial diet, community service, Samia Cynthia, eri silkworm.

\begin{abstract}
Abstrak
Ulat sutera merupakan serangga bernilai ekonomi tinggi. Kepompong ulat sutera dapat dijadikan bahan dasar pembuatan kain sutera dengan harga jual yang tinggi. Kelompok Usaha Jantra Mas Sejahtera (JAMTRA) merupakan kelompok usaha kain sutera yang melakukan usaha dari hulu ke hilir secara mandiri mulai dari pemeliharaan ulat sutera, pengolahan benang dan kain sutera, serta desain produk kain sutera. Dalam hal pemeliharaan ulat sutera, kelompok usaha JAMTRA mengahadapi permasalahan seperti kurangnya pemahaman mengenai cara memperbanyak serangga dengan baik, dan kurangnya pengetahuan mengenai pakan buatan untuk perbanyakan serangga. Kegiatan ini bertujuan meningkatkan pengetahuan peternak ulat sutera dalam memperbanyak serangga berdasar sifat ekologi serangga dan melatih peternak ulat sutera dalam membuat pakan buatan. Hasil kegiatan menunjukkan bahwa pakan berhasil digunakan bagi ulat sutera. Namun demikian, tidak ada kepompong yang terbentuk. Sehingga, kegiatan lanjutan diperlukan untuk memodifikasi komposisi pakan agar dapat digunakan dalam perbanyak ulat sutera secara maksimal.
\end{abstract}

Kata Kunci: Pakan buatan, pengabdian masyarakat, Samia cynthia, ulat sutera.

Submitted: 2020-09-22 Revised: 2020-10-06 Accepted: 2020-10-09

\section{Pendahuluan}

Serangga merupakan kelompok mahluk hidup dengan keanekaragaman yang tinggi. Selain keanekaragamannya yang tinggi, serangga juga memiliki banyak manfaat bagi kehidupan manusia seperti penyerbuk (Goulson, 2003), penghasil madu (winston, 1991), pengasil lak (Guang-Ji et al., 1984), indikator lingkungan (Rainio \& Niemelä, 2003), bahkan ada serangga yang bermanfaat dalam bidang forensik, kesehatan, juga mendatangkan nilai ekonomi (Borror et al., 1989). Salah satu serangga yang memiliki nilai ekonomi adalah ulat sutera. Kepompong ulat sutera dapat diolah menjadi benang dan kain dengan harga jual yang mahal. Kain sutera biasanya dihasilkan dari ulat Bombyx mori golongan ngengat Ordo Lepidoptera Famili Bombicidae (Guntoro, 1994). 
Namun tidak demikian pada kelompok usaha Jantra Mas Sejahtera (JAMTRA) di Desa Sendangsari, Kecamatan Pengasih, Kulon Progo, Yogyakarta. Kelompok usaha ini bergerak dalam bidang produksi ulat sutera dari ulat Samia cynthia. Ulat ini satu ordo dengan ulat sutera $B$. mori namun berasal dari famili yang berbeda. Walaupun berbeda, sutera yang dihasilkan dari ulat Samia memiliki kualitas yang bagus laikanya sutera Bombyx. Perbedaan lainnya adalah bahwa ulat Samia berkembang biak pada tanaman singkong. Menariknya, ulat ini hanya memakan daun tua sehingga tidak menimbulkan kerusakan yang menyebabkan kerugian besar.

Kelompok usaha JAMTRA memulai usaha pada tahun 2017. Awal mula pengembangan usaha, peternak Samia hanya berjumlah 2 orang. Tiga tahun berjalan, peternak telah bertambah menjadi 16 orang seiring berkembangnya usaha yang tidak hanya memperbanyak ulat sebagai bahan baku pembuat benang, namun usaha berkembang sampai pembuatan kain bahkan pakaian dan benda lain berbahan dasar sutera Samia. Bahkan, beberapa pihak asing pun telah ada yang tertarik untuk belajar

memperbanyak ulat sutera Samia.

Selain memperbanyak jumlah peternak ulat Samia. Manajemen usaha pun mengalami perkembangan. Untuk produksi benang, kelompok usaha JAMTRA memiliki alat pintal sendiri dan bekerjasama dengan pabrik pintal untuk menghasilkan benang dan kain dalam jumlah lebih banyak dengan kualitas yang lebih baik. Saat ini kelompok usaha JAMTRA juga menjalin kerjasama dengan beberapa galeri busana untuk bidang pemasaran. Namun demikian, beberapa permasalahan masih dihadapi kelompok usaha ini. Salah satunya adalah masalah dalam beternak ulat sebagai bahan baku benang sutera Samia itu sendiri. Untuk mendapatkan kain yang banyak, tentu diperlukan jumlah kepompong yang banyak pula. Semakin banyak benang atau kain yang ingin dihasilkan, jumlah ulat yang diternak juga harus semakin banyak. Hal ini berkaitan dengan pakan yang diberikan untuk memelihara ulat yaitu pakan alami berupa daun singkong yang ratarata diberikan sebanyak $5 \mathrm{~kg} /$ hari ( $\pm 150 \mathrm{~kg}$ per bulan).

Selama ini perbanyakan ulat dilakukan di rumah warga. Ruang pemeliharaan dilakukan di ruang pemeliharaan serangga yang terbuka. Ulat dipelihara pada rak pemeliharaan tanpa menggunakan wadah. Hal ini dapat mengancam produksi sutera Samia karena perbanyakan di ruang terbuka membuka peluang munculnya serangga predator maupun infeksi patogen yang dapat menurunkan populasi ulat Samia. Perbanyakan tanpa wadah pemeliharaan dapat menurunkan kualitas pakan. Dari situasi dan kondisi tersebut, terdapat dua perumusan masalah yaitu:

1. Kurangnya pemahaman mengenai cara memperbanyak serangga karena keterbatasan ilmu dan pengetahuan tentang entomologi, dan

2. Kurangnya pengetahuan mengenai pakan buatan untuk perbanyakan serangga.

Maka dari itu dilakukan kegiatan pengabdian masyarakat dengan tujuan meningkatkan pengetahuan peternak ulat sutera dalam memperbanyak serangga berdasar sifat ekologi serangga dan melatih peternak ulat sutera dalam membuat pakan buatan. Kegiatan ini diharapkan meningkatkan pengetahuan dan keterampilan peternak sehingga dapat menambah kualitas benang dan kain sutera yang dihasilkan. 


\section{Metode}

Kegiatan dilaksanakan pada bulan Maret sampai September 2020 bertempat di laboratorium Proteksi Tanaman, Fakultas Pertanian, Universitas Muhammadiyah Yogyakarta. Khalayak sasaran pada kegiaatan ini adalah Kelompok Usaha Jantra Mas Sejahtera (JAMTRA) yang beralamat di Desa Paingan, Kecamatan Pengasih, Kulon Progo, Yogyakarta.

Metode yang digunakan pada kegiatan ini berupa penyuluhan/edukasi (Gambar 1), pelatihan (Gambar 2) dan pendampingan. Penyuluhan dilakukan dengan mengumpulkan beberapa anggota Kelompok Usaha Jantra Mas Sejahtera (JAMTRA) untuk mengikuti pelatihan mengenai cara perbanyakan serangga. Kegiatan dilakukan terhadap 5 anggota Kelompok Usaha mengingat kondisi pandemi yang belum berakhir. Kegiatan dilakukan dengan mengikuti standar protokol kesehatan yang berlaku. Peserta pelatihan selanjutnya akan bertugas untuk mengedukasi anggota lainnya.

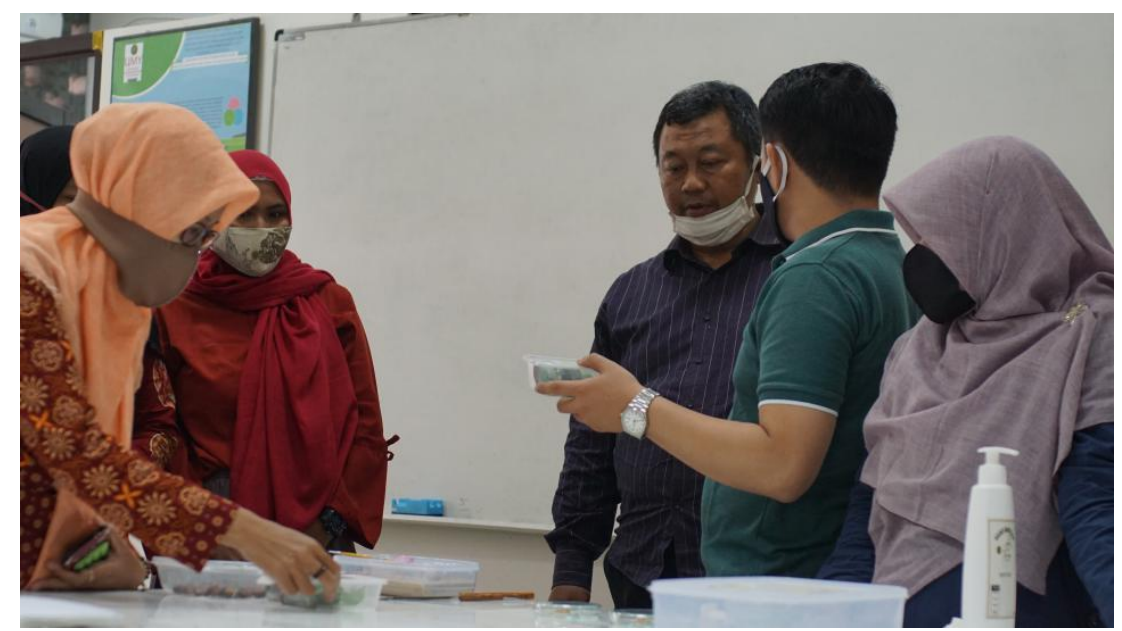

Gambar 1. Peserta belajar cara memperbanyak serangga berdasar ekologinya

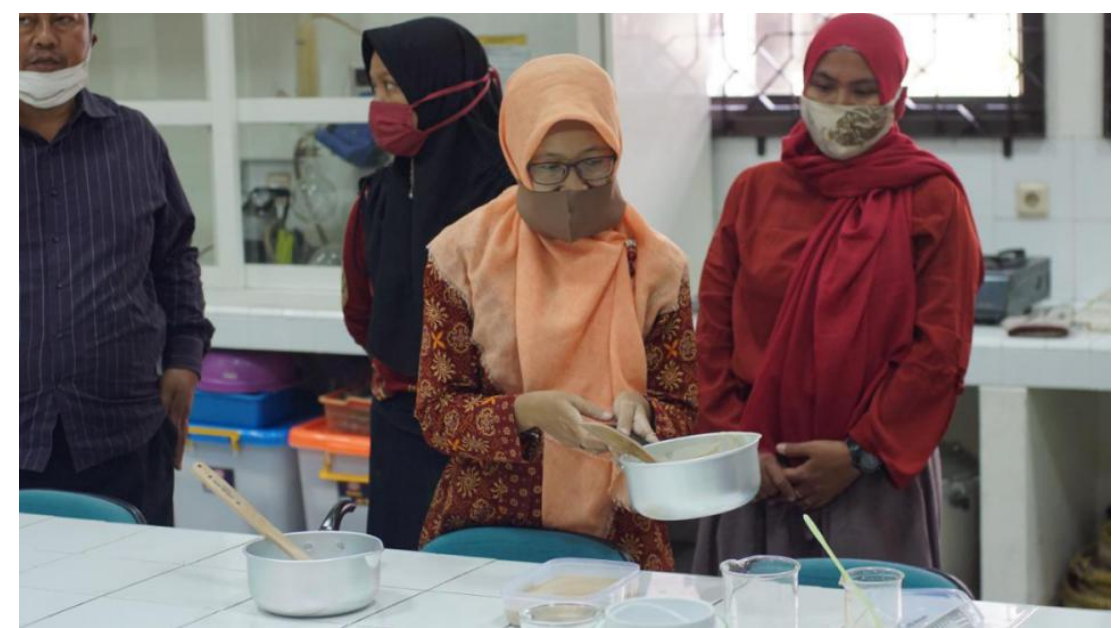

Gambar 2. Peserta melakukan praktik pembuatan pakan buatan

Kegiatan pelatihan perbanyakan serangga yang dilakukan mencakup penyiapan alat dan tempat, cara memelihara telur, ulat, kepompong, serangga dewasa, dan cara 
memanen telur. Aspek penting yang disampaikan kepada peserta adalah manajemen populasi ulat melalui modifikasi siklus hidup. Hal ini dilakukan sebagai upaya rekayasa lingkungan untuk mendapatkan kebutuhan jumlah serangga agar sesuai dengan kebutuhan produksi.

Sementara itu, kegiatan pelatihan pembuatan pakan buatan dilakukan dengan memberikan cerama terlebih dahulu mengenai penggunaan pakan buatan dalam perbanyakan serangga dan kemudian diikuti dengan praktik pembuatan pakan buatan. Pakan yang dibuat merupakan pakan buatan yang biasa dipakai untuk serangga ordo Lepidoptera dengan mengacu pada Ranganath et al. (2006) yang dimodifikasi. Pakan yang telah dibuat kemudian diujicobakan pada serangga uji untuk melihat kemampuan penerimaan pakan yang terjadi.

Sementara itu, kegiatan pendampingan dilakukan sebagai upaya pemantauan pemeliharaan serangga dengan menggunakan pakan buatan yang telah dibuat. Kegiatan pemantauan dilakukan dengan cara komunikasi secara tidak langsung.

\section{Hasil dan Pembahasan}

Serangga merupakan mahluk hidup yang hidup pada tumbuhan. Kebutuhan nutrisi serangga diperoleh dari tumbuhan sebagai makanannya. Perilaku makan serangga pada tanaman budidaya menyebabkan serangga dikategorikan sebagai hama tanaman apabila menyebabkan kerusakan pada tingkat tinggi. Apabila kerusakan tidak menimbulkan kerugian secara ekonomi, maka kehadiran serangga pada tanaman dikatakan tidak mengganggu secara berarti. Sama hal nya dengan Samia cynthia, ulat sutera yang hidup pada pohon singkong sebagai makanan utamanya (Tungjitwitayakul \& Tatun, 2017). Meskipun memiliki perilaku makan yang rakus, Samia hanya makan daun tua sehingga tidak menjadi hama utama bagi tanaman. Selain makan daun singkong, Samia juga dapat hidup dengan memakan daun jarak, dan Ketapang (Subramanianan et al. 2013).

Kehadiran ulat sutera Samia dinilai mampu memberikan keuntungan bagi manusia, cangkang kepompong ulat ini mampu dipintal menjadi benang sebagai bahan kain sutera bernilai ekonomi tinggi. Karena itu, ada banyak orang yang melakukan usaha budidaya ulat sutera Samia. Sama halnya dengan Kelompok Usaha JAMTRA yang telah lama melakukan usaha budidaya ulat Samia bahkan sampai produksi benang dan kain sutera Samia. Selama ini, para peternak di Kelompok Usaha JAMTRA memelihara Samia dengan pakan yang diberikan berupa pakan alami yaitu daun jarak dan atau daun singkong. Hal ini dapat menjadi kendala karena keterbatasan jumlah tanaman di lapangan. Selain itu, jumlah populasi telur yang tinggi pun terkadang menjadi tidak termanfaatkan secara maksimal (dibuang) karena terlalu banyaknya populasi yang sudah pasti akan memerlukan jumlah pakan yang banyak. Maka dari itu, kegiatan ini dilakukan untuk meningkatkan pengetahuan peternak ulat sutera dalam memperbanyak serangga berdasar sifat ekologi serangga dan melatih peternak ulat sutera dalam membuat pakan buatan.

Ulat sutera Samia merupakan serangga yang melalui proses metamorfosis secara sempurna mulai dari telur, larva/ulat, pupa/kepompong, dan serangga dewasa berupa ngengat. Telur memiliki lama waktu perkembangan selama 7-10 hari, larva \pm 14 hari, kepompong \pm 14 hari, dan serangga dewasa hidup selama 4-5 hari. Satu serangga 
dewasa mampu menghasilkan sebanyak 300-400 telur selama hidupnya (Kedir et al. 2014). Apabila tingkat penetasan telur sekitar 90\%, maka akan didapat jumlah larva instar satu sebanyak 200-300 larva per-ngengat. Jumlah ini tentu sangat banyak dan akan memerlukan pakan dalam jumlah banyak pula. Untuk itu, dapat dilakukan manajemen populasi dengan menyimpan telur dan atau pupa dalam lemari es bersuhu stabil untuk memperlambat perkembangan serangga. Perkembangan serangga dapat menjadi lebih lambat pada suhu tertentu (Du Plessis et al., 2020). Sehingga, perkembangan siklus hidup serangga dapat ditunda. Manajemen populasi ini dilakukan untuk mendapat jumlah anakan yang tidak terlalu banyak sehingga penyediaan pakan pun dapat terpenuhi dengan mudah. Selain itu, adanya manajemen populasi serangga bermanfaat dalam memfasilitasi ketersediaan serangga setiap saat sehingga produksi benang dan kain dapat dilakukan setiap hari. Selama ini, Kelompok Usaha JAMTRA dapat memproduksi benang dan kain pada saat tertentu tergantung ketersediaan pupa Samia. Dengan adanya manajemen populasi, produksi benang dan ataupun kain dapat ditingkatkan sehingga dapat dilakukan kapan pun.

Selain dengan menerapkan manajemen populasi serangga, pemberian pakan buatan juga dapat menjadi solusi penyediaan pakan. Pada pelatihan ini, dilakukan edukasi tentang pembuatan pakan buatan mencakup bahan-bahan dasar yang digunakan, fungsi setiap bahan, cara pembuatan, penyimpanan, dan pemberian kepada serangga. Bahanbahan yang digunakan merupakan bahan yang digunakan untuk membuat pakan buatan bagi serangga lepidoptera atau kupu-kupu pada umumnya. Pakan dibuat dengan cara dimasak dan kemudian disajikan dalam wadah. Proses pembuatan pakan buatan ini dilakukan mirip dengan langkah-langkah membuat agar-agar (Gambar 3).
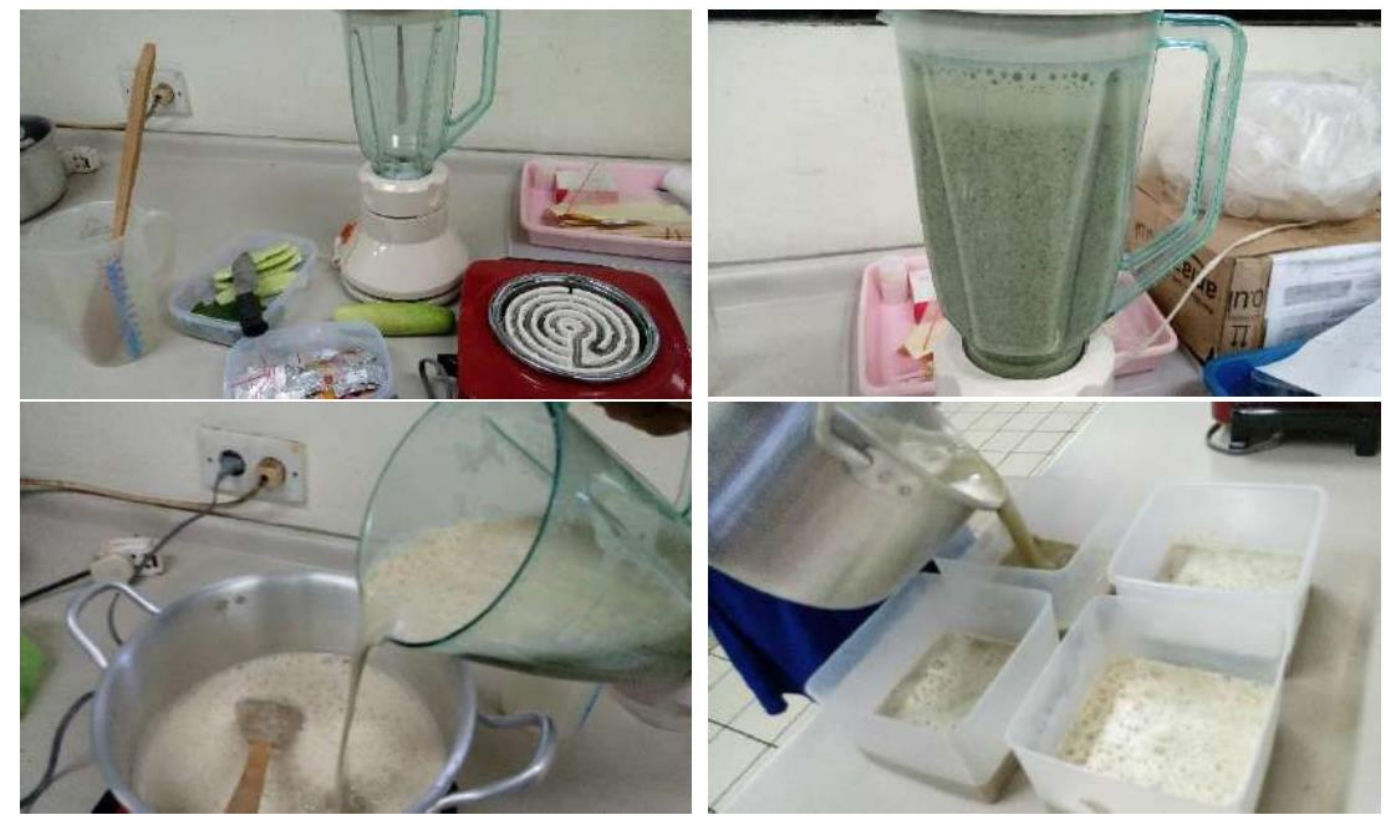

Gambar 3. Proses pembuatan pakan buatan

Setelah pakan dibuat, pakan disimpan dalam lemari es agar tahan lama. Pakan diberikan dalam bentuk blok $(2 \times 2 \mathrm{~cm})$. pakan diberikan kepada larva instar 1 yang 
diperoleh dari penangkaran Kelompok Usaha JAMTRA. Pakan diberikan setiap hari dan perkembangan larva diamati. Daun sinkong diberikan sebagai pakan alami kontrol bagi ulat sutera Samia. Hasil pengamatan menunjukkan bahwa aktifitas makan mulai teramati sejak awal pakan buatan diberikan. Hanya saja, aktiftas makan yang terjadi tidak seaktif perilaku makan pada pakan alami. Hal ini mungkin terjadi karena proses penerimaan (adaptasi) belum terjadi secara utuh. Perilaku makan terus terjadi sampai larva memasuki instar 4 tanpa adanya perubahan ukuran tubuh yang mengakibatkan larva mati pada saat memasuki instar 5 (Tabel 1). Hal ini mungkin terjadi karena nutrisi yang terkandung dalam pakan buatan hanya mendukung aktifitas makan dan tidak mencukupi untuk kebutuhan melengkapi siklus hidup. Dengan demikian, diperlukan upaya modifikasi agar pakan buatan yang ada dapat menunjang kehidupan ulat Samia secara maksimal.

Tabel 1. Perkembangan ulat Samia yang diberi pakan buatan vs alami

\begin{tabular}{lccccccc}
\hline Jenis pakan & \multicolumn{7}{c}{ Stadia larva } \\
\cline { 2 - 8 } & Instar 1 & Instar 2 & Instar 3 & Instar 4 & Instar 5 & Pupa & Dewasa \\
\hline Pakan buatan & $\mathrm{v}$ & $\mathrm{v}$ & $\mathrm{v}$ & $\mathrm{v}$ & mati & - & - \\
Daun Singkong & $\mathrm{v}$ & $\mathrm{v}$ & $\mathrm{v}$ & $\mathrm{v}$ & $\mathrm{v}$ & $\mathrm{v}$ & $\mathrm{v}$ \\
\hline
\end{tabular}

v: larva berada dalam kondisi hidup

\section{Kesimpulan}

Kegiatan pengabdian masyarakat dengan tujuan meningkatkan pengetahuan dan keterampilan peternak ulat sutera di Kelompok Usaha Jantra Mas Sejahtera telah dilakukan dengan baik. Kepala Kelompok Usaha sendiri menuturkan bahwa pelatihan pembuatan pakan merupakan hal baru bagi mereka. Para peternak tidak pernah tahu adanya pakan buatan yang dapat digunakan dalam memperbanyak serangga. Sehingga, kegiatan ini benar-benar menambah pengetahuan para peternak dan meningkatkan keterampilan peternak dalam membuat pakan buatan dan memelihara serangga sesuai ekologi serangga itu sendiri.

\section{Daftar Pustaka}

Borror, D. J., Triplehorn, C. A., \& Johnson, N. F. (1989). An introduction to the study of insects. Saunders college publishing.

Du Plessis, H., Schlemmer, M. L., \& Van den Berg, J. (2020). The effect of temperature on the development of Spodoptera frugiperda (Lepidoptera: Noctuidae). Insects, 11(4), 228.

Goulson, D. (2003). Conserving wild bees for crop pollination. Journal of Food Agriculture and Environment, 1, 142-144.

Guntoro, S. (1994). Budi Daya Ulat Sutera. Yogyakarta, Indonesia: Kanisius.

Kedir, S., Emana, G., \& Waktole, S. (2014). Rearing performance of eri-silkworm (Samia cynthia ricini Boisduval) (Lepidoptera: Saturniidae) fed with different castor (Ricinus communis L.) genotypes. Journal of Entomology, 11(1), 25-33.

Rainio, J., \& Niemelä, J. (2003). Ground beetles (Coleoptera: Carabidae) as bioindicators. Biodiversity \& Conservation, 12(3), 487-506. 
Ranganath, H. R., Gangavisalakshy, P. N., \& Kumar, N. K. (2006). An artificial diet for mass multiplication of the gherkin fruit borer, Diaphania indica (Saunders) (Lepidoptera: Pyralidae). Pest Management in Horticultural Ecosystems, 12(1), 3740.

Subramanianan, K., Sakthivel, N., \& Qadri, S. M. H. (2013). Rearing technology of eri silkworm (Samia cynthia ricini) under varied seasonal and host plant conditions in Tamil Nadu. International Journal of Life Sciences Biotechnology and Pharma Research, 2(2), 130-141.

Tungjitwitayakul, J., \& Tatun, N. (2017). Comparison of biological and biochemical parameters of erisilkworms, Samia cynthia ricini (Lepidoptera: Saturniidae), reared on artificial and natural diets. Journal of Entomology Zoology Studies, 5(2), 314319.

Winston, M. L. (1991). The biology of the honeybee. Harvard university press. 